\title{
Salvianolic Acid B Ameliorates Cognitive Deficits Through IGF-1/Akt Pathway in Rats with Vascular Dementia
}

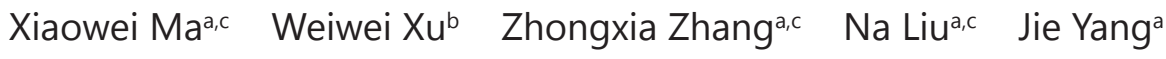 \\ Mingwei Wang ${ }^{a, c}$ Yanyong Wang ${ }^{a, c}$ \\ aDepartment of Neurology, the First Hospital of Hebei Medical University, Shijiazhuang, Hebei, \\ bepartment of Cardiology, the First Hospital of Hebei Medical University, Shijiazhuang, Hebei, 'Brain \\ Aging and Cognitive Neuroscience Laboratory of Hebei Province, Shijiazhuang, Hebei, PR China
}

\section{Key words}

Salvianolic acid B • Vascular dementia • Cognitive impairment • IGF-1 • Akt

\begin{abstract}
BackgroundAims: Salvianolic acid B (SalB) is a natural polyphenolic compound enriched in Salvia miltiorrhiza Bunge. Our study was designed to explore the role of Sal B on cognitive impairment in vascular dementia (VD) model rats, as well as its possible molecular mechanisms. Methods: Rats were randomly divided into four groups ( $n=15$ for each group): Control group, Sal B group (normal Sprague Dawley rats treated with Sal B), VD group and VD + Sal B group. The VD group rats were established by permanent bilateral common carotid artery occlusion (BCCAO). Animals in the Control and Sal B group received the same operation without bilateral common carotid arteries occlusion. The animals in Sal B group and VD + Sal B group received Sal B $(20 \mathrm{mg} / \mathrm{kg})$ orally once a day for consecutive 6 weeks. We investigated the effects of SalB on BCCAO-induced cognitive deficits rats models via the Morris water maze experiment. To explore the mechanisms of Sal B on cognitive function, we detected the expression of IGF-1, Akt and p-Akt, and the rate of cell apoptosis in CA1 region. Results: Our results observed that hippocampal IGF-1 was decreased in VD model rats, while SalB reversed the alteration of IGF1 levels. The expression of hippocampal Akt showed no significant difference between control and VD group, however, p-Akt level was significantly decreased in VD group. After 6 weeks of SalB treatment, p-Akt level was significantly increased. A large number of apoptotic neurons were found in VD model rats, while SalB prevented apoptosis of hippocampal neurons in CA1 region in VD model rats. Conclusion: SalB significantly ameliorated cognitive deficits in $B C C A O$-induced VD model rats. The potential mechanism underlying the protective effects may be mediated through IGF-1/Akt pathway.

X. Ma and W. Xu contributed equally to this work and share first authorship.

Yanyong Wang

KARGER
Department of Neurology, The first hospital of Hebei Medical University

89, Dong-gang Road, Shijiazhuang, Hebei province, (P.R. China)

Tel. +860311 85917040, E-Mail wangziyi100811@163.com 


\section{Cellular Physiology Cell Physiol Biochem 2017;43:1381-1391 \begin{tabular}{ll|l} 
and Biochemistry Published online: October 09, 2017 & $\begin{array}{l}\text { (c) } 2017 \text { The Author(s). Published by S. Karger AG, Basel } \\
\text { www.karger.com/cpb }\end{array}$ \\
\hline
\end{tabular} \\ Ma et al.: Salb and Vascular Dementia}

\section{Introduction}

Vascular dementia (VD), the second most common type of dementia after Alzheimer's disease in humans globally, is characterized by a progressive decline in cognitive function $[1,2]$. VD is a clinical mental disorder caused by cardiovascular pathological changes and cerebrovascular disease, which can lead to ischemic, ischemic-hypoxic or hemorrhagic brain tissue lesions [3, 4]. VD in turn increases the risk of recurrent cerebrovascular disease, dependent living and death. With the increasing age of the population and improved survival rates from cerebrovascular diseases, VD may affect more individuals in the future. The increasing incidence of VD impose a heavy social and economic burden on individuals, families, communities and countries. Up to now, there is no effective treatment for VD and the exact pathogenesis of VD are still elusive. In consequence, the effective treatment for VD is urgently needed.

Salvianolic acid B (SalB) is a natural polyphenolic compound enriched in Salvia miltiorrhiza Bunge [5]. SalB has a variety of pharmacological effects for its anti-inflammatory and anti-oxidative activities [6]. A large number of research have been used SalB to treat cardiovascular diseases [7, 8]. Recently, SalB is demonstrated effective in diabetic rats, obesity for its role of regulating glucose and lipid metabolism $[9,10]$. SalB is also widely used in diseases of nervous system. For instance, SalB could attenuated the cognitive decline in mice with traumatic brain injury and A $325-35$ peptide-induced Alzheimer's disease [1113]. However, no research have been focused on the cognitive enhancing effects of SalB in VD. If SalB ameliorates cognitive deficits caused by chronic cerebral hypoperfusion, it would become a candidate drug of enhancing cognitive function for treating VD.

Although the precise mechanisms underlying VD is unknown, chronic cerebral hypoperfusion is regarded as a main underlying pathogenesis for VD. Bilateral common carotid artery occlusion (BCCAO), a suitable model for exploring the mechanisms of VD, can mimick chronic cerebral hypoperfusion in rats [14]. In the present study, we investigated the effects of SalB on BCCAO-induced cognitive deficits rats models via the Morris water maze experiment. Research [15] have reported downregulated expression of IGF-1 and p-Akt were related to the cognitive deficits in VD. TherFefore, whether SalB affects IGF-1/Akt signal pathway in VD model rats is interesting. The purpose of our research was to investigate whether SalB could ameliorate memory deficits in VD rats and, if so, What are the potential mechanisms.

\section{Materials and Methods}

Animals and Model induction

Adult healthy male Sprague-Dawley (SD) rats (aged 2 months, weighed 200-240 g) were acquired from the Experimental Animal Center of Hebei Medical University. All rats were raised in a house with a 12 hour light-dark cycle and $22-25^{\circ} \mathrm{C}$ temperature. All rats housed 2 or 3 per cage and had access to food and water ad libitum. The experimental protocol was performed in compliance with the regulations approved by the Committee on the Ethics of Animal Experiments of the Hebei Medical University.

The vascular dementia models were made via permanent bilateral common carotid artery occlusion (BCCAO). Rats were anesthetized with $10 \%$ chloral hydrate (35 mg/100 g) by intraperitoneal injection. The skin of the rat was incised along the midline of the neck region and the bilateral common carotid arteries were exposed. Then the bilateral common carotid arteries were tied with silk sutures. The wound was sutured and animals were returned to the cage for recovery from the anesthesia. Rats in control group were received the same operation without bilateral common carotid arteries occlusion.

Animal groups and drug application

Sal B was obtained from phytomarker Ltd. (Tianjin, China), and its purity was detected to be more than 98\% by high-performance liquid chromatography. Rats were randomly divided into four groups $(\mathrm{n}=15$ for each group): Control group, Sal B group (normal Sprague Dawley rats administered with Sal B), VD group 


\section{Cellular Physiology Cell Physiol Biochem 2017;43:1381-1391 \begin{tabular}{l|l|l} 
and Biochemistry Published online: October 09, 2017 & $\begin{array}{l}\text { (c) } 2017 \text { The Author(s). Published by S. Karger AG, Basel } \\
\text { www.karger.com/cpb }\end{array}$ \\
\hline
\end{tabular} \\ Ma et al.: Salb and Vascular Dementia}

and VD + Sal B group. The VD group rats were established by BCCAO. Animals in the Control and Sal B group were received the same operation without bilateral common carotid arteries occlusion. The animals in Sal B group and VD + Sal B group were received Sal B $(20 \mathrm{mg} / \mathrm{kg})$ orally once a day for consecutive 6 weeks, while the rats in Control group and VD group administered with saline orally.

Morris water maze (MWM) test

The Morris water maze test was performed to evaluate spatial learning and memory performance of rats. Tests were carried out four times per day for 5 consecutive days with an interval between sessions of 40-60min. The Morris water maze consists of a large black cylindrical pool (200 $\mathrm{cm}$ in diameter and $60 \mathrm{~cm}$ in height) filled

Table 1. The sequences of four different start positions

\begin{tabular}{lcccc}
\hline Day & Trial 1 & Trial 2 & Trial 3 & Trial 4 \\
\hline 1 & $\mathrm{~N}$ & $\mathrm{E}$ & $\mathrm{SE}$ & $\mathrm{NW}$ \\
2 & $\mathrm{SE}$ & $\mathrm{N}$ & $\mathrm{NW}$ & $\mathrm{E}$ \\
3 & $\mathrm{NW}$ & $\mathrm{SE}$ & $\mathrm{E}$ & $\mathrm{N}$ \\
4 & $\mathrm{E}$ & $\mathrm{NW}$ & $\mathrm{N}$ & $\mathrm{SE}$ \\
5 & $\mathrm{~N}$ & $\mathrm{SE}$ & $\mathrm{E}$ & $\mathrm{NW}$ \\
6 (Probe) & $\mathrm{NE}$ & & & \\
\hline
\end{tabular}
with $22 \pm 2^{\circ} \mathrm{C}$ nontoxic black water $(45 \mathrm{~cm}$ in depth). The pool was divided into 4 quadrants and a removable circular hidden platform $(10 \mathrm{~cm}$ in diameter and $2 \mathrm{~cm}$ below the surface of the water) was placed in the center of the target quadrant. In the 5 days of navigation test, rats were released facing the pool wall in one of the four different start positions and allowed to swim freely to the hidden platform. The sequences of four different start positions list in Table 1. The time of each rat taken to climb onto the hidden platform was recorded as the escape latency. If a rat escape onto the platform within $120 \mathrm{~s}$, it was allowed to stay there for $20 \mathrm{~s}$. If a rat could not reach the hidden platform within $120 \mathrm{~s}$, it was guided to the platform and stay there for $20 \mathrm{~s}$, and the escape latency was recorded as $120 \mathrm{~s}$. On day 6, the probe trial was tested by removing the platform and a rat was allowed to swim freely to find the missing platform for $120 \mathrm{~s}$. The performance of rats were recorded and analyzed by a video tracking system. The times across the platform and escape latency were recorded.

\section{ELISA Analysis}

After MWM test, 5 rats of each group were sacrificed and hippocampal homogenates were prepared. The expression of IGF-1, Akt and p-Akt were tested by specific ELISA kit followed the manufacturer's instructions (Cusabio Biotech, China).

\section{Western Blotting Analysis}

The expression of IGF-1, Akt and p-Akt were tested by Western blotting analysis. Rats of each group were anesthetized and the brain was obtain, then the hippocampus were rapidly dissected on the ice. The hippocampus was homogenized in RIPA assay lysis buffer. The proteins were subsequently separated by electrophoresis on $10 \%$ polyacrylamide gels and transferred onto polyvinylidene difluoride membranes. The membrane was blocked with 5\% dried, defatted milk in TBS buffer for $2 \mathrm{~h}$ at room temperature and then incubated with primary antibodies anti Akt (1:1000, Cell Signaling, USA), p-Akt (Ser473) (1:1000, Cell Signaling, USA), IGF1 (1:1000, Cell Signaling, USA), and $\beta$-actin (1:2000, Cell Signaling, USA) at $4^{\circ} \mathrm{C}$ overnight. After several washes, the membranes were incubated with the horseradish peroxidase-conjugated secondary antibodies for $1 \mathrm{~h}$ at room temperature. The membranes were detected by a chemiluminescent system. The protein bands were measured by image analysis software. All relative optical densities were normalized to $\beta$-actin.

\section{Semi-quantitative reverse transcription PCR (semi-RT-PCR) assay}

Qiagen Rneasy mini kit (74014) was used to isolate total RNA from the hippocampus tissue. Then, primescript RT kit (Takara, Japan) and PCR ExTaq (Takara) were used to perform reverse transcription PCR according to the manufacturer's protocol. The primer sequences were $5^{\prime}$-TGTGATCTGAGGAGGCTGGA-3' and 5'-GCAAAGGATCTTGCGGTGAC-3' for IGF-1 (216 bp), and 5'-GGTCAGAAGGATTCCTATGTG-3'and $5^{\prime}$-ATTGCCAATGGTGACCTG-3' for $\beta$-actin (599bp). The amplified PCR products were then resolved by electrophoresis on a $1.5 \%$ agarose gel and analyzed by Quantity one software (Bio-Rad). The expression levels of IGF-1 mRNA were normalized to $\beta$-actin. 


\section{Cellular Physiology Cell Physiol Biochem 2017;43:1381-1391 \begin{tabular}{ll|l} 
DOI: 10.1159/000481849 & $\begin{array}{l}\text { O } 2017 \text { The Author(s). Published by S. Karger AG, Basel } \\
\text { www.karger.com/cpb }\end{array}$ \\
\hline
\end{tabular}

Hippocampal morphology observation

Rats were anesthetized with $10 \%$ chloral hydrate (35 mg/100 g) by intraperitoneal injection. After Perfusion the brain tissue was obtained, then fixed by $4 \%$ polyformaldehyde solution for 24 hours. Dehydrated by gradient ethanol, be transparent by dimethylbenzene, waxed and embedded, then serially sectioned coronally. HE staining was performed to observe the morphologic changes in hippocampal neurons.

\section{TUNEL staining}

The apoptosis of neurons in hippocampal CA1 region from the four groups were tested by TUNEL staining. The brain tissue was fixed in 4\% PFA and embedded into paraffin wax. In Situ Cell Death Detection Kit (Roche, Switzerland) was applied to test the apoptosis followed the manufacturer's instructions. Three sections were used for each group, and five fields were randomly selected from each section $(\times 400)$. Images were measured using Image-Pro Plus 6.0 software (Olympus Co., Tokyo, Japan). The apoptotic rate was calculated. Apoptotic rate $=$ (number of apoptotic cells/total number of cells) $\times 100 \%$.

\section{Statistical analysis}

Data are expressed as the mean \pm SD. Statistical analysis was performed using SPSS 17.0 software. In the MWM test, escape latency was analyzed by twoway repeated measures ANOVA followed by LSD post hoc test. All other data were analyzed by one-way ANOVA. Statistically significant was set at $\mathrm{p}<0.05$.

\section{Results}

Sal $B$ ameliorated cognitive deficits in VD model rats

We evaluated the cognitive function in different groups by the MWM experiment to determine whether Sal B ameliorates cognitive deficits (Fig. 1). There were no significant differences in cognitive function between the Control group and the Sal B group, demonstrating that Sal B did not influence cognitive function in normal animals. The escape latency was significantly increased in VD model rats compared to Control group. However, the escape latency was significantly decreased after 6 weeks of Sal B treatment (Fig. 1A). In the probe test, the times across the platform was significantly decreased in the VD group compared to the Control group (Fig. 1B). The times across the platform was significantly increased

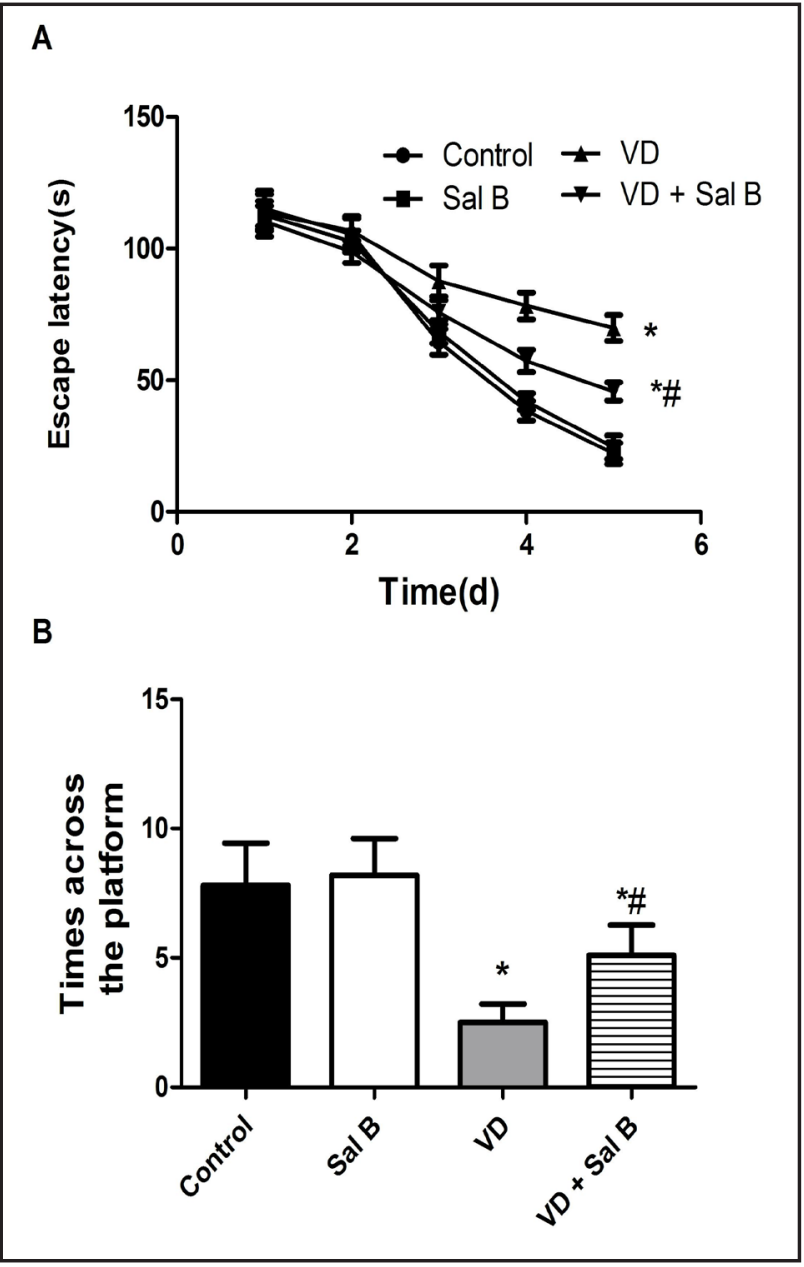

Fig. 1. Results of MWM experiment. (A) The escape latency was significantly increased in VD model rats compared to Control group. However, the escape latency was significantly decreased after 6 weeks of Sal B treatment. (B) The times across the platform was significantly decreased in the VD group compared to the Control group, the times across the platform was significantly increased in the VD + Sal B group compared to the VD group. There were no significant differences in cognitive function between the Control group and the Sal B group. ${ }^{*} \mathrm{p}<0.05$ vs. Control group. $\# \mathrm{p}<0.05$ vs. VD group.

\section{KARGER}




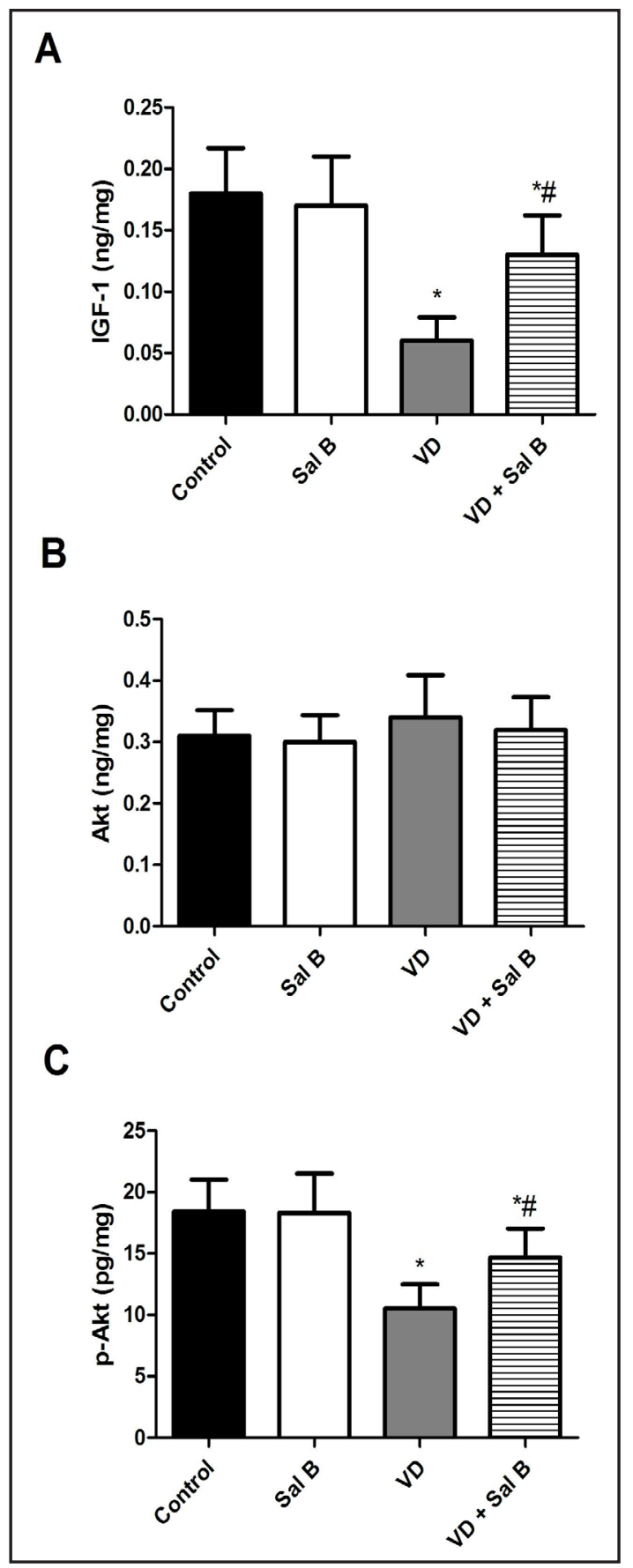

Fig. 2. Quantification of hippocampal IGF-1, Akt and p-Akt protein levels tested by ELISA. (A) IGF-1. (B) Akt. (C) p-Akt. The expression of IGF-1 and pAkt in the VD group were significantly decreased than the Control group. However, the expression of IGF-1 and p-Akt were significantly increased in the VD + Sal B group. There were no significant differences between the Control group and the Sal B group. The expression of Akt showed no significant difference among different groups. ${ }^{*} \mathrm{p}<0.05$ vs. Control group. \#p<0.05 vs. VD group.

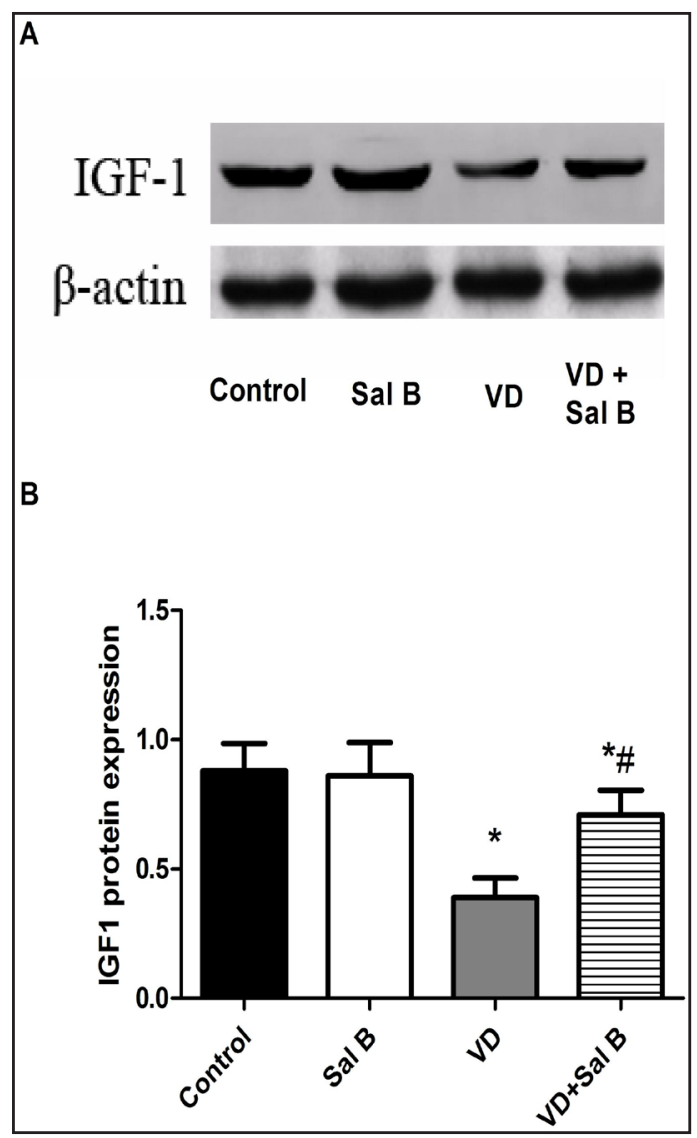

Fig. 3. Western blotting analysis of IGF-1 expression. (A) IGF-1 and $\beta$-actin protein bands. (B) The relative protein expression of IGF-1. The expression of hippocampal IGF-1 in the VD group was significantly decreased than the Control group. However, the expression of hippocampal IGF-1 was significantly increased in the VD + Sal B group. ${ }^{*} \mathrm{p}<0.05$ vs. Control group. \#p<0.05 vs. VD group.

in the VD + Sal B group compared to the VD group.

Sal B increased IGF-1 expression in VD model rats

Western blotting and ELISA results showed that the expression of hippocampal IGF-1 in the VD group was significantly decreased than the Control group. However, the expression of hippocampal IGF-1 was significantly increased in VD + Sal B group (Fig. 2A and Fig. 3). RT-PCR results showed that the mRNA expression of hippocampal IGF-1 in the VD group was significantly decreased than the Control group. However, the mRNA expression of hippocampal IGF1 was significantly increased in VD + Sal

\section{KARGER}




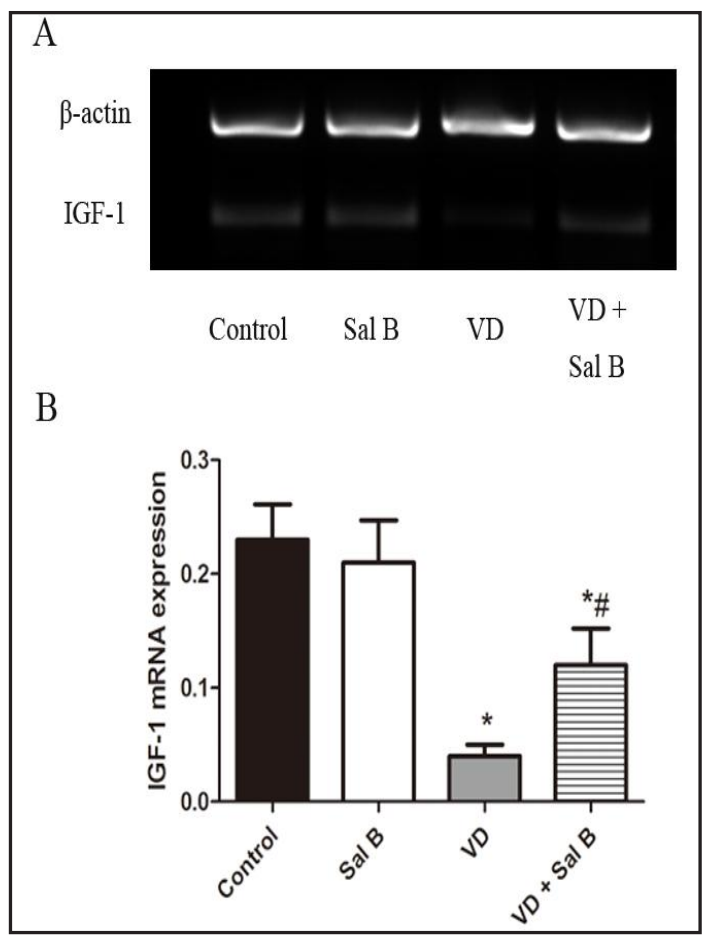

Fig. 4. RT-PCR analysis of IGF-1 expression. (A) IGF1 and $\beta$-actin mRNA bands. (B) The relative mRNA expression of IGF-1. The expression of hippocampal IGF-1 in the VD group was significantly decreased than the Control group. However, the expression of hippocampal IGF-1 was significantly increased in the VD + Sal B group. * $\mathrm{p}<0.05$ vs. Control group. \#p $<0.05$ vs. VD group.

Fig. 6. Western blotting analysis of p-Akt expression. (A) p-Akt and $\beta$-actin protein bands. (B) The relative protein expression of $\mathrm{p}$-Akt. The expression of $\mathrm{p}$-Akt was significantly decreased in VD group compared to Control group. After 6 weeks of SalB treatment, p-Akt level was significantly increased. ${ }^{*} \mathrm{p}<0.05$ vs. Control group. \#p<0.05 vs. VD group.

B group (Fig. 4). There were no significant differences between the Control group and the Sal B group. Our results suggested that BCCAO inhibited the expression of hippocampal IGF1 , while SalB reversed the alteration of IGF-1 levels.

Sal $B$ increased $p$-Akt expression in VD model rats

Western blotting and ELISA results revealed that the expression of hippocampal Akt showed no significant difference among different groups (Fig. 2B and Fig. 5). BCCAO
A

Akt

$\beta$-actin

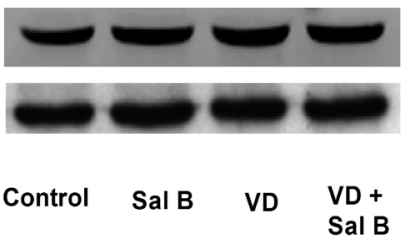

B

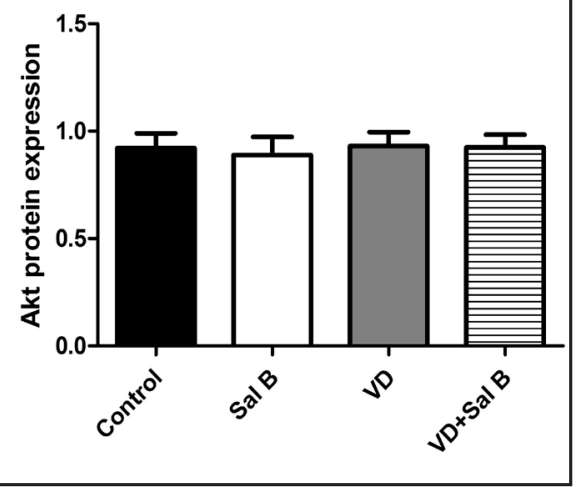

Fig. 5. Western blotting analysis of Akt expression. (A) Akt and $\beta$-actin protein bands. (B) The relative protein expression of Akt. The expression of hippocampal Akt showed no significant difference among different groups. ${ }^{*} \mathrm{p}<0.05$ vs. Control group. $\# \mathrm{p}<0.05$ vs. VD group.

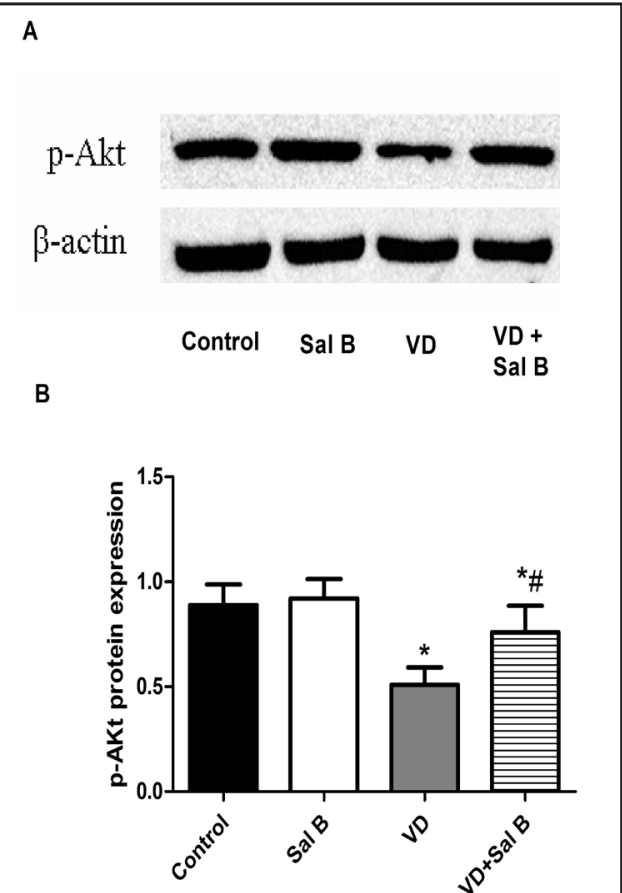


Fig. 7. Morphologic changes in hippocampal neurons. (A) Control group, (B)Sal B group, (C)VD group, (D) VD + Sal B group. In Control and Sal B group the neurons in CA1 region were tightly aligned, cytoplasm and nuclei were clear. In VD group the neurons in CA1 region were disorganized and loose, the cells became smaller, appeared chromatic agglutination and karyopyknosis. In VD + Sal B group, the normal neurons were more than VD group, and chromatin is richer than VD group, cell arrangement were tighter than VD group.

Fig. 8. Sal B prevented apoptosis of hippocampal neurons in CA1 region in VD model rats. (A) A few apoptotic neurons were found in Control group. (B) A few apoptotic neurons were found in Sal B group. (C) Significant increase of apoptotic neurons were found in VD group. (D) The apoptotic neurons were decreased in VD + Sal B group. (E) Quantification of the apoptotic neurons. ${ }^{*} \mathrm{p}<0.05$ vs. Control group. \#p<0.05 vs. VD group.

and SalB had no obvious effect on Akt level. However, p-Akt level was significantly decreased in VD group compared to Control group. After 6 weeks of SalB treatment, p-Akt level was significantly increased (Fig. 2C and Fig. 6). Our results suggested that SalB treatment improves cognitive impairment in VD rats partly through phosphorylation of Akt rather than by regulating its Akt levels.

Morphologic changes in hippocampal neurons

In Control and Sal B group the neurons in CA1 region were tightly aligned, cytoplasm and nuclei were clear. In VD group the neurons in CA1 region were disorganized and loose, the cells became smaller, appeared

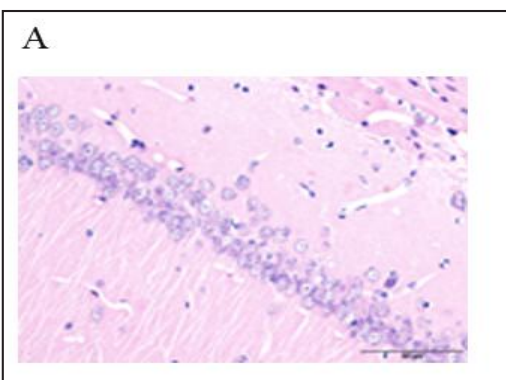

C
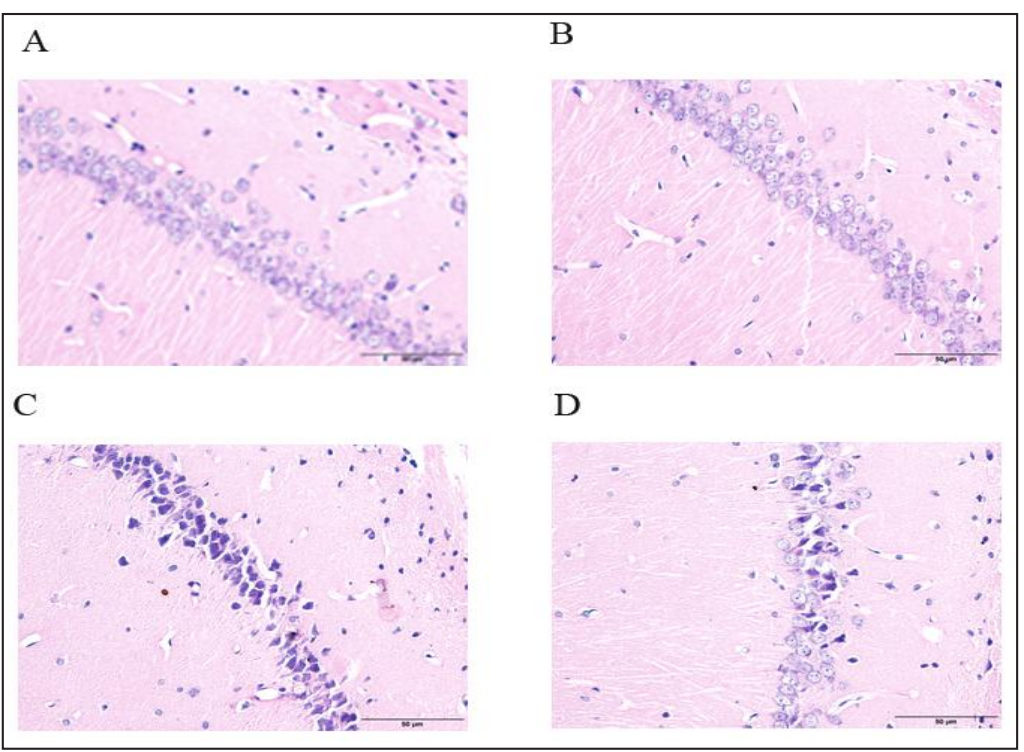

D

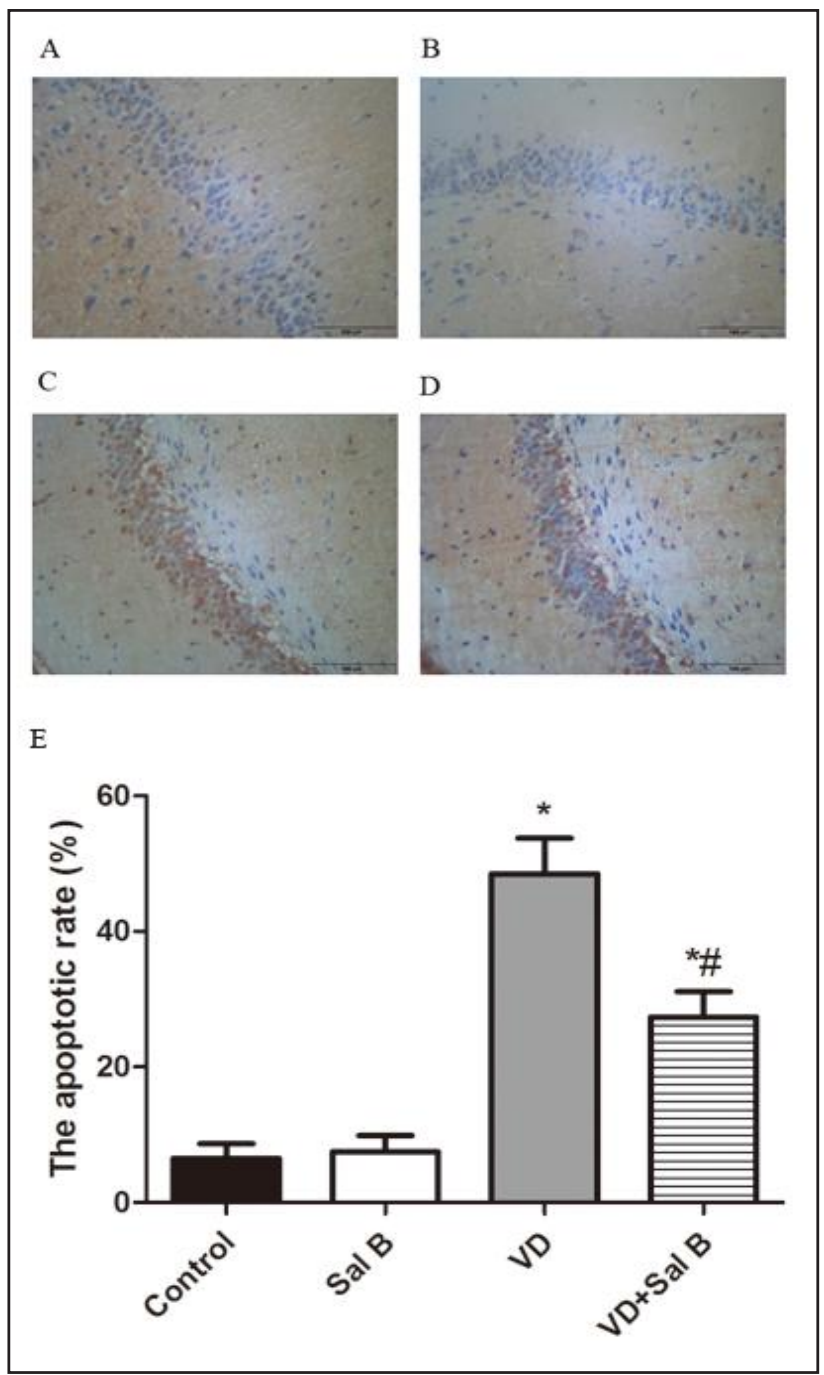




\section{Cellular Physiology Cell Physiol Biochem 2017;43:1381-1391 and Biochemistry \begin{tabular}{c|c|c|} 
DOI: 10.1159/000481849 & Published onn'ine: October 09, 2017 & $\begin{array}{l}\text { O } 2017 \text { The Author(s). Published by S. Karger AG, Basel } \\
\text { www.karger.com/cpb }\end{array}$ \\
\cline { 2 - 3 }
\end{tabular} \\ Ma et al.: Salb and Vascular Dementia}

chromatic agglutination and karyopyknosis. In VD + Sal B group, the normal neurons were more than VD group, and chromatin is richer than VD group, cell arrangement were tighter than VD group. See (Fig. 7)

\section{Sal B prevented apoptosis of hippocampal neurons in CA1 region in VD model rats}

The rate of cell apoptosis in CA1 region was remarkably increased in the VD group than in the Control group $(\mathrm{p}<0.05)$. The rate of cell apoptosis in the hippocampal CA1 region was significantly decreased in the VD + Sal B group than in the VD group $(\mathrm{p}<0.05)$. There were no significant differences in apoptotic rate between the Control group and the Sal B group ( $p>0.05$ ). See (Fig. 8). Our results suggested that the SalB treatment efficiently decreased cell apoptosis in the hippocampal CA1 region.

\section{Discussion}

SalB, a natural polyphenolic compound enriched in Salvia miltiorrhiza Bunge, possess a variety of pharmacological effects, for instance, anti-inflammatory, anti-oxidative, glucose regulated and neuroprotective activities $[10,16,17]$. Although a large number of research have demonstrated the close relationship between Sal B and cognitive ability, the underlying mechanisms remain elusive. Meanwhile, no research have been focused on the cognitive enhancing effects of SalB in VD. Therefore, we investigated the effects of Sal B on cognitive deficits in BCCAO-induced VD model rats. Our result showed that VD rats accompanied by cognitive decline while SalB ameliorates the memory impairments of VD model rats. SalB ameliorates cognitive deficits caused by chronic cerebral hypoperfusion, it would become a candidate neuroprotective drug of enhancing cognitive function for treating VD.

Insulin-like growth factor-1 (IGF-1), a small single-chain polypeptide (7.5 kDa), is widely expressed in several parts of the central nervous system, such as the cerebral cortex, cerebellum, hypothalamus and hippocampus [18]. IGF-1 is a multifunctional polypeptide essential for neuroprotection, normal growth and development [19]. IGF-1 exerts its roles on brain development through control of neurotrophic responses and cell signalling [20]. IGF- 1 could decrease the glycogen synthase kinase 3 and the $A \beta$ level in the brain $[21,22]$, and the reduction of IGF- 1 is associated with $A \beta$ deposit and cognitive impairment [23]. Several prospective studies demonstrated a close correlation between serum IGF-I levels and cognitive status in the elderly $[24,25]$. All the research mentioned above demonstrated the important role of IGF-1 in maintaining cognitive function. There also some researches focus the neuroprotective effects of IGF-1 on treating cerebral ischemic brain injury [26, 27]. Gong et al. [15] reported IGF-1/IGF-1R signaling system may involved in the onset and development of VD. Therefore, whether SalB affects IGF-1 expression in VD model rats is interesting. To investigate the mechanisms underlying the cognitive enhancing effects of SalB in BCCAO-induced VD model rats, we examined the expression of IGF-1. Our results observed that hippocampal IGF-1 was decreased in VD model rats, while SalB reversed the alteration of IGF-1 levels. Our research suggest that SalB improved the cognitive performance in BCCAO-induced VD model rats partly through enchancing hippocampal IGF-1 expression.

Akt, a downstream target of phosphatidylinositide 3 kinase (PI3K), is a serine /threonine kinase taken part in cell survival [28]. Activated Akt promotes cell survival and inhibits apoptosis by phosphorylating its down-stream proteins, such as caspase-9, Bcl-2-associated death protein (Bad), glycogen synthase kinase 3 $\beta$ (GSK3 $\beta$ )[29-31]. IGF-1 binding to its receptor may activate one of the two major intracellular signaling pathways, PI3K/Akt and mitogen activated protein kinase (MAPK) pathways [32]. The neuroprotective effects of IGF1 is mainly activated by the PI3K/Akt pathway [33]. Research have reported downregulated expression of IGF-1 and p-Akt were related to the cognitive deficits in VD [15]. Improvement of Akt expression is an attractive neural protection goal for the Akt pathway modulates cell survival after stroke [34]. To investigate the mechanisms underlying the cognitive enhancing effects of SalB in VD model rats, we examined the expression of Akt and p-Akt as well. In 


\section{Cellular Physiology Cell Physiol Biochem 2017;43:1381-1391 \begin{tabular}{l|l|l} 
DOI: 10.1159/000481849 & $\begin{array}{l}\text { O } 2017 \text { The Author(s). Published by S. Karger AG, Basel } \\
\text { www.karger.com/cpb }\end{array}$ \\
\hline and Biochemistry Published online: October 09, 201 &
\end{tabular}

our study, the expression of hippocampal Akt showed no significant difference between control and VD group, however, p-Akt level was significantly decreased in VD group. After 6 weeks of SalB treatment, p-Akt level was significantly increased. SalB improves cognitive impairment in VD rats partly through phosphorylation of Akt rather than by regulating its protein levels. Our results suggest that Akt pathway plays an important role in the SalBinduced improvement of the cognitive performance.

Apoptosis is an important type of active cell death and an important way for pyramid neuron loss, which has been specifically clarified previously. It is characterized by cytoplasmic condensation, pyknotic nuclei and DNA fragmentation, which can be labeled by TUNEL staining of single or double strands break in DNA. Research have reported chronic cerebral hypoperfusion could promote apoptosis [35]. Our results observed that a large number of apoptotic neurons in VD model rats, while SalB prevented apoptosis of hippocampal neurons in CA1 region in VD model rats. It has been shown that IGF-1 increased cell viability while decreasing apoptosis [36]. Our research suggest that SalB inhibited apoptosis of hippocampal neurons in VD model rats maybe through enchancing hippocampal IGF-1 expression.

\section{Conclusion}

Taken together, in our present study, we found that the cognitive performance, associated with the expression of IGF-1 and p-Akt were significantly increased in the SalB-treated VD rats than those in the VD model rats. SalB also prevented apoptosis of hippocampal neurons in CA1 region in VD model rats. Therefore, we speculated that SalB has the beneficial neuroprotective effect to VD. This study could provide valuable experimental basis for VD clinical treatment. The neuroprotective effects of SalB may be associated with IGF-1/Akt pathway, but the molecular mechanisms remain to be further explored, for example, whether it related to neurogenesis, neuroinflammation and synaptic plasticity etc.

\section{Acknowledgements}

This work was supported by a grant from government funding project for the excellent talents of clinical medicine at the provincial level (361034) to Yanyong Wang.

\section{Disclosure Statement}

We declare that we have no conflicts of interest in the authorship or publication of this contribution.

\section{References}

1 Roman GC: Facts, myths, and controversies in vascular dementia. J Neurol Sci 2004;226:49-52.

$\checkmark 2$ Jellinger KA: The enigma of vascular cognitive disorder and vascular dementia. Acta Neuropathol 2007;113:349-388.

-3 Roman GC: Vascular dementia revisited: diagnosis, pathogenesis, treatment, and prevention. Med Clin North Am 2002;86:477-499.

-4 Seitz DP, Adunuri N, Gill SS, Gruneir A, Herrmann N, Rochon P: Antidepressants for agitation and psychosis in dementia. Cochrane Database Syst Rev 2011;10. DOI:1002/14651858.CD008191.pub2.

5 Huang MQ Zhou CJ, Zhang YP, Zhang XQ Xu W, Lin J, Wang PJ: Salvianolic Acid B Ameliorates Hyperglycemia and Dyslipidemia in db/db Mice through the AMPK Pathway. Cell Physiol Biochem 2016;40:933-943. 


\section{Cellular Physiology Cell Physiol Biochem 2017;43:1381-1391 \begin{tabular}{l|l|l} 
DOI: 10.1159/000481849 & $\begin{array}{l}\text { O 2017 The Author(s). Published by S. Karger AG, Basel } \\
\text { www.karger.com/cpb }\end{array}$ \\
\hline
\end{tabular} \\ Ma et al.: Salb and Vascular Dementia}

6 Liu YR, Qu SX, Maitz MF, Tan R, Weng J: The effect of the major components of Salvia Miltiorrhiza Bunge on bone marrow cells. J Ethnopharmacol 2007;111:573-583.

7 Lin C, Liu Z, Lu Y, Yao Y, Zhang Y, Ma Z, Kuai M, Sun X, Sun S, Jing Y, Yu L, Li Y, Zhang Q Bian H: Cardioprotective effect of Salvianolic acid B on acute myocardial infarction by promoting autophagy and neovascularization and inhibiting apoptosis. J Pharm Pharmacol 2016;68:941-952.

-8 Deng Y, Yang M, Xu F, Zhang Q Zhao Q, Yu H, Li D, Zhang G, Lu A, Cho K, Teng F, Wu P, Wang L, Wu W, Liu X, Guo DA, Jiang B: Combined Salvianolic Acid B and Ginsenoside Rg1 Exerts Cardioprotection against Ischemia/Reperfusion Injury in Rats. PLoS One 2015;10:e0135435.

-9 Wang P, Xu S, Li W, Wang F, Yang Z, Jiang L, Wang Q, Huang M, Zhou P: Salvianolic acid B inhibited PPARgamma expression and attenuated weight gain in mice with high-fat diet-induced obesity. Cell Physiol Biochem 2014;34:288-298.

10 Huang M, Wang P, Xu S, Xu W, Xu W, Chu K, Lu J: Biological activities of salvianolic acid B from Salvia miltiorrhiza on type 2 diabetes induced by high-fat diet and streptozotocin. Pharm Biol 2015;53:10581065.

-11 Kim DH, Park SJ, Kim JM, Jeon SJ, Kim DH, Cho YW, Son KH, Lee HJ, Moon JH, Cheong JH, Ko KH, Ryu JH: Cognitive dysfunctions induced by a cholinergic blockade and Abeta 25-35 peptide are attenuated by salvianolic acid B. Neuropharmacology 2011;61:1432-1440.

12 Durairajan SS, Yuan Q, Xie L, Chan WS, Kum WF, Koo I, Liu C, Song Y, Huang JD, Klein WL, Li M: Salvianolic acid B inhibits Abeta fibril formation and disaggregates preformed fibrils and protects against Abetainduced cytotoxicty. Neurochem Int 2008;52:741-750.

13 Chen T, Liu W, Chao X, Zhang L, Qu Y, Huo J, Fei Z: Salvianolic acid B attenuates brain damage and inflammation after traumatic brain injury in mice. Brain Res Bull 2011;84:163-168.

14 Li YW, Li QY, Wang JH, Xu XL: Contribution of p38 MAPK to the Ameliorating Effect of Enriched Environment on the Cognitive Deficits Induced by Chronic Cerebral Hypoperfusion. Cell Physiol Biochem 2016;40:549-557.

15 Gong X, Ma M, Fan X, Li M, Liu Q, Liu X, Xu G: Down-regulation of IGF-1/IGF-1R in hippocampus of rats with vascular dementia. Neurosci Lett 2012;513:20-24.

16 Xu S, Zhong A, Ma H, Li D, Hu Y, Xu Y, Zhang J: Neuroprotective Effect of Salvianolic Acid B Against Cerebral Ischemic Injury in Rats via the CD40/NF-kappaB Pathway Associated with Suppression of Platelets Activation and Neuroinflammation. Brain Res 2017;1661:37-48.

17 Zhang JQ, Wu XH, Feng Y, Xie XF, Fan YH, Yan S, Zhao QY, Peng C, You ZL: Salvianolic acid B ameliorates depressive-like behaviors in chronic mild stress-treated mice: involvement of the neuroinflammatory pathway. Acta Pharmacol Sin 2016;37:1141-1153.

18 de Pablo F, de la Rosa EJ: The developing CNS: a scenario for the action of proinsulin, insulin and insulinlike growth factors. Trends Neurosci 1995;18:143-150.

19 Leinninger GM, Feldman EL: Insulin-like growth factors in the treatment of neurological disease. Endocr Dev 2005;9:135-159.

20 Hoshaw BA, Hill TI, Crowley JJ, Malberg JE, Khawaja X, Rosenzweig-Lipson S, Schechter LE, Lucki I: Antidepressant-like behavioral effects of IGF-I produced by enhanced serotonin transmission. Eur J Pharmacol 2008;594:109-116.

21 Hong M, Lee VM: Insulin and insulin-like growth factor-1 regulate tau phosphorylation in cultured human neurons. J Biol Chem 1997;272:19547-19553.

-22 Carro E, Trejo JL, Gomez-Isla T, LeRoith D, Torres-Aleman I: Serum insulin-like growth factor I regulates brain amyloid-beta levels. Nat Med 2002;8:1390-1397.

23 Sakata K, Mastin JR, Duke SM, Vail MG, Overacre AE, Dong BE, Jha S: Effects of antidepressant treatment on mice lacking brain-derived neurotrophic factor expression through promoter IV. Eur J Neurosci 2013;37:1863-1874.

24 Tumati S, Burger H, Martens S, van der Schouw YT, Aleman A: Association between Cognition and Serum Insulin-Like Growth Factor-1 in Middle-Aged \& Older Men: An 8 Year Follow-Up Study. PLoS One 2016;11:e0154450.

25 Aleman A, Verhaar HJ, De Haan EH, De Vries WR, Samson MM, Drent ML, Van der Veen EA, Koppeschaar HP: Insulin-like growth factor-I and cognitive function in healthy older men. J Clin Endocrinol Metab 1999;84:471-475. 


\section{Cellular Physiology Cell Physiol Biochem 2017;43:1381-1391 \begin{tabular}{ll|l} 
DOI: 10.1159/000481849 & $\begin{array}{l}\text { O 2017 The Author(s). Published by S. Karger AG, Basel } \\
\text { www.karger.com/cpb }\end{array}$ \\
\hline
\end{tabular} \\ Ma et al.: Salb and Vascular Dementia}

-26 Liu XF, Fawcett JR, Thorne RG, Frey WH, 2nd: Non-invasive intranasal insulin-like growth factor-I reduces infarct volume and improves neurologic function in rats following middle cerebral artery occlusion. Neurosci Lett 2001;308:91-94.

-27 Zhu W, Fan Y, Frenzel T, Gasmi M, Bartus RT, Young WL, Yang GY, Chen Y: Insulin growth factor-1 gene transfer enhances neurovascular remodeling and improves long-term stroke outcome in mice. Stroke 2008;39:1254-1261.

-28 Datta SR, Brunet A, Greenberg ME: Cellular survival: a play in three Akts. Genes Dev 1999;13:2905-2927.

29 Franke TF, Hornik CP, Segev L, Shostak GA, Sugimoto C: PI3K/Akt and apoptosis: size matters. Oncogene 2003;22:8983-8998.

30 Hanada M, Feng J, Hemmings BA: Structure, regulation and function of PKB/AKT--a major therapeutic target. Biochim Biophys Acta 2004;1697:3-16.

31 Balendran A, Casamayor A, Deak M, Paterson A, Gaffney P, Currie R, Downes CP, Alessi DR: PDK1 acquires PDK2 activity in the presence of a synthetic peptide derived from the carboxyl terminus of PRK2. Curr Biol 1999;9:393-404.

-32 Russo VC, Gluckman PD, Feldman EL, Werther GA: The insulin-like growth factor system and its pleiotropic functions in brain. Endocr Rev 2005;26:916-943.

-33 Zheng WH, Kar S, Quirion R: Insulin-like growth factor-1-induced phosphorylation of transcription factor FKHRL1 is mediated by phosphatidylinositol 3-kinase/Akt kinase and role of this pathway in insulin-like growth factor-1-induced survival of cultured hippocampal neurons. Mol Pharmacol 2002;62:225-233.

34 Zhu C, Wang X, Xu F, Qiu L, Cheng X, Simbruner G, Blomgren K: Intraischemic mild hypothermia prevents neuronal cell death and tissue loss after neonatal cerebral hypoxia-ischemia. Eur J Neurosci 2006;23:387393.

-35 Liu Z, Hu M, Lu P, Wang H, Qi Q, Xu J, Xiao Y, Fan M, Jia Y, Zhang D: Cerebrolysin alleviates cognitive deficits induced by chronic cerebral hypoperfusion by increasing the levels of plasticity-related proteins and decreasing the levels of apoptosis-related proteins in the rat hippocampus. Neurosci Lett 2017;651:72-78.

-36 Zhao B, Zheng Z: Insulin Growth Factor 1 Protects Neural Stem Cells Against Apoptosis Induced by Hypoxia Through Akt/Mitogen-Activated Protein Kinase/Extracellular Signal-Regulated Kinase (Akt/MAPK/ERK) Pathway in Hypoxia-Ishchemic Encephalopathy. Med Sci Monit 2017;23:1872-1879. 